\title{
ST6GAL1: A key player in cancer (Review)
}

\author{
REBECCA GARNHAM, EMMA SCOTT, KAREN E. LIVERMORE and JENNIFER MUNKLEY
}

\author{
Institute of Genetic Medicine, Newcastle University, International Centre for Life, Newcastle Upon Tyne NE1 3BZ, UK
}

Received April 16, 2019; Accepted June 4, 2019

DOI: $10.3892 / 01.2019 .10458$

\begin{abstract}
Aberrant glycosylation is a universal feature of cancer cells and there is now overwhelming evidence that glycans can modulate pathways intrinsic to tumour cell biology. Glycans are important in all of the cancer hallmarks and there is a renewed interest in the glycomic profiling of tumours to improve early diagnosis, determine patient prognosis and identify targets for therapeutic intervention. One of the most widely occurring cancer associated changes in glycosylation is abnormal sialylation which is often accompanied by changes in sialyltransferase activity. Several sialyltransferases are implicated in cancer, but in recent years ST6 $\beta$-galactoside $\alpha$-2,6-sialyltransferase 1 (ST6GAL1) has become increasingly dominant in the literature. ST6GAL1 catalyses the addition of $\alpha 2,6$-linked sialic acids to terminal N-glycans and can modify glycoproteins and/or glycolipids. ST6GAL1 is upregulated in numerous types of cancer (including pancreatic, prostate, breast and ovarian cancer) and can promote growth, survival and metastasis. The present review discusses ST6GAL in relation to the hallmarks of cancer, and highlights its key role in multiple mechanisms intrinsic to tumour cell biology.
\end{abstract}

\section{Contents}

1. Introduction

2. Altered ST6GAL1 in cancer

3. ST6GAL1 in the hallmarks of cancer

4. Conclusions and future perspectives

\section{Introduction}

Glycosylation is an enzymatic process that links glycan sugars to other glycans, lipids or proteins and is essential to virtually every biological process (1). The complete pattern of glycan

Correspondence to: Dr Jennifer Munkley, Institute of Genetic Medicine, Newcastle University, International Centre for Life, Central Parkway, Newcastle Upon Tyne NE1 3BZ, UK

E-mail: jennifer.munkley@ncl.ac.uk

Key words: glycosylation, glycans, sialylation, ST6 $\beta$-galactoside $\alpha$-2,6-sialyltransferase 1 , hallmarks of cancer modifications in a cell or tissue (known as 'the glycome') is assembled by the synchronised action of numerous glycosylation enzymes on glycoproteins and/or lipids (2). Changes to the glycome are well documented in cancer, and aberrant glycosylation is not just a consequence, but also a driver of a malignant phenotype (3). The hallmarks of cancer were originally described in 2000 and refer to capabilities acquired during the multi-step development of cancer to enable cancer cells to survive, proliferate and metastasise (4). They include sustaining proliferative signalling, evading growth suppressors, resisting cell death, enabling replicative immortality, inducing angiogenesis, and activating invasion and metastasis. Underpinning these hallmarks are genome instability and inflammation which contribute to multiple hallmark capabilities (4). In 2011 two next generation cancer hallmarks were proposed (reprogramming of energy metabolism and evading immune destruction) and the 'tumour microenvironment' was recognised as contributing to the acquisition of hallmark traits (5).

Although not included in the original and next generation hallmarks, aberrant glycosylation is now also widely recognised as a new hallmark of cancer causally associated with all of the hallmark capabilities $(2,3,6)$. One of the most widely occurring cancer associated changes in glycosylation is abnormal sialylation, which is often driven by the altered expression of sialyltranserase enzymes (7-9) and is linked to poor patient prognosis and metastasis (10-13). Several sialyltransferase enzymes are implicated in cancer, but in recent years ST6GAL1 (which catalyses the addition of $\alpha 2,6$-linked sialic acids onto terminal $\mathrm{N}$-glycans) has become increasingly dominant in the literature. ST6GAL1 is upregulated in numerous types of cancer, including pancreatic, prostate, breast and ovarian cancer, and is has key roles in tumour aggression and metastasis (14-18). Here, we discuss ST6GAL in the context of the original and emerging hallmarks of cancer, and highlight its role in pathways intrinsic to tumour cell biology (Fig. 1).

\section{Altered ST6GAL1 in cancer}

ST6GAL1 levels are upregulated in several carcinomas, as is the degree of $\alpha 2,6$-sialylation (15-17,19-26) (Table I). In particular, elevated ST6GAL1 is often correlated with high tumour grade, metastasis and reduced patient prognosis. In both prostate and breast cancer, ST6GAL1 expression correlates with a more aggressive tumour grade $(16,27)$, and in ovarian cancer levels increase in advanced stage disease (18). Tumours with elevated 
ST6GAL1 expression are thought to be more invasive and metastatic, evidenced by increased lymphovascular invasion, deep stromal invasion, distant metastasis and neighbouring vesicle invasion $(16,28,29)$. ST6GAL1 is also associated with reduced recurrence-free intervals and a poorer overall survival in ovarian, prostate and pancreatic cancer $(16,18,28,30)$. The only exception is bladder cancer, where ST6GAL1 is believed to have a tumour suppressive role (31).

\section{ST6GAL1 in the hallmarks of cancer}

Activating invasion and metastasis. The ability of cancer cells to invade and spread is central to the development of an invasive, malignant tumour. This development, which promotes local invasion and distant metastasis is a multistep process referred to as the invasion-metastasis cascade (5). The process is regulated via complex crosstalk across several signalling pathways and transcription factors, resulting in an epithelial to mesenchymal transition (EMT) of cancer cells (32). EMT is an example of cellular phenotype switching, characterised by a loss of epithelial markers in favour of the migratory phenotype of mesenchymal cells $(33,34)$. The literature demonstrating a relationship between sialylation and the acquisition of invasive and metastatic phenotypes is extensive (13,35-41). Further to this, ST6GAL1 upregulation has been shown to induce a more invasive, migratory cell phenotype in gastric, colon, liver, prostate, ovarian, breast and cervical cancers $(16,17,42,43)$. ST6GAL1 gene knockdown and over expression experiments in vitro have demonstrated its capacity to regulate the invasive and metastatic features of cancer cells in several cell types $(16,24,35,42-44)$. In 2017 , a prominent glyco-oncology study identified elevated $S T 6 G A L 1$ as part of a pro-metastatic gene signature in melanoma tumours (29). ST6GAL1 is also increased in patients with metastatic cervical cancer $(7,43)$, where levels correlate with stromal invasion, metastatic spread to the lymph nodes and poor patient prognosis (43). Similarly, in triple-negative breast cancer, ST6GAL1 levels are linked to metastasis and reduced survival times (19), and high ST6Gal1 in ovarian cancer is associated with lymphovascular invasion and distant metastasis (7). In breast cancer cells, overexpression of ST6GAL increases the turnover of cell surface E-cadherin and promotes TGF- $\beta$-induced EMT providing a potential mechanistic link between ST6GAL1-mediated sialylation and metastasis (17).

Sustained proliferative signalling. Central to cancer cell biology is the excessive capacity to proliferate, and to do so in the absence of proliferative stimuli $(4,45)$. Sialylation has been shown to alter proliferative signalling cascades in different cancers $(24,46)$. ST6GAL1 in particular can regulate cellular proliferation in hepatocellular carcinoma (HCC), as shown through gene knockdown and overexpression studies carried out in the MHCC97L HCC cell line. The HCC in vitro studies suggested that overexpression of ST6GAL1 in HCC cells increased activation of the PI3K/Akt signalling pathway (42). Hyper-activation of the PI3K signalling cascade is well documented in several different cancer subtypes as regulating and promoting hyper-proliferation of oncogenic cells (47-50). If ST6GAL1 can activate PI3K/Akt signalling, as suggested by Zhao et al (42) this may point towards mechanistic link between ST6GAL1 upregulation and increased cellular proliferation. Similar effects on proliferation and PI3K/Akt signalling have also been observed following ST6GAL1 gene silencing in the DU145 and PC-3 prostate cancer cell lines. Wei et al (16) observed approximately a two-fold decrease in cancer cell proliferation following ST6GAL1 gene silencing. It is important to note that this relationship has only been observed in HCC and prostate cancer, and is contradicted by findings generated using glioma cells, assessing the relationship between ST6GAL1 and proliferative capacity. In this instance, ST6GAL1 overexpression did not perpetuate hyper-proliferation (23). This contradiction could suggest that the effect of ST6GAL1 on proliferative signalling may be exclusive to specific cancer subtypes.

Enabling replicative immortality. In the seminal 2000 'hallmarks of cancer' paper, replicative immortality was outlined as being essential to develop and sustain macroscopic tumours $(4,5)$. This innate replicative potential, without the threat of cellular senescence has been termed immortalization and is underpinned by telomere abnormalities or oncogenic induced cellular senescence. Several key oncogene or tumour suppressor genes have a role in promoting oncogenic induced cellular senescence (including Tp53, RAS, c-MYC and PTEN) and some have been shown to be targets for glycosylation (51-56). As outlined previously, ST6GAL1 can regulate PI3K/AKT signalling, a known RAS effector cascade $(16,57)$. ST6GAL1 gene knockdown in prostate cancer cells results in decreased levels of $P I 3 K / A K T / G S K-3 \beta$ and $\beta$-catenin signalling molecules (16). B-catenin, a member of the Wnt signalling pathway, has a well-defined oncogenic activity and has been well characterised as an enabler of replicative immortality through direct activation of telomerase reverse transcriptase (TERT) $(58,59)$. Sialylation by ST6GAL1 upregulates several oncogenes crucial for the immortalization of cancer cells, interacting with RAS effector pathways, and $\mathrm{Wnt} / \beta$-catenin signalling. Known downstream effects of these pathways result in telomerase repression and oncogenic induced stress, thereby indicating a role for ST6GAL1 in enabling replicative immortality (52).

Sustained angiogenesis. For a cancer to sustain macroscopic tumour development and promote metastasis, the formation of neovasculature is necessary for the supply of nutrients and oxygen. This process, known as angiogenesis, is tightly regulated by opposing factors; stimulating and inhibiting the receptors displayed on the surface of vascular endothelial cells $(4,5,60,61)$. Although key molecular regulators of angiogenesis have been identified, such as VEGF and TSP-1, it is now widely accepted that regulation of angiogenesis is a highly complex process, heavily influenced by the tumour microenvironment, gaining influence from things such as tumour metabolism, immune infiltrate and cancer-associated fibroblasts (CAFs) (62). Abnormal glycosylation changes have been identified throughout several pro-angiogenic pathways in cancers, and recently it was found that VEGF-induced angiogenesis was dependent upon sialylation of the VEGF-receptor 2 (VEGFR2) (63-68). A high profile Cell paper, published in 2014, concluded that cancer cells can undergo hypoxia induced glycan remodelling which can 


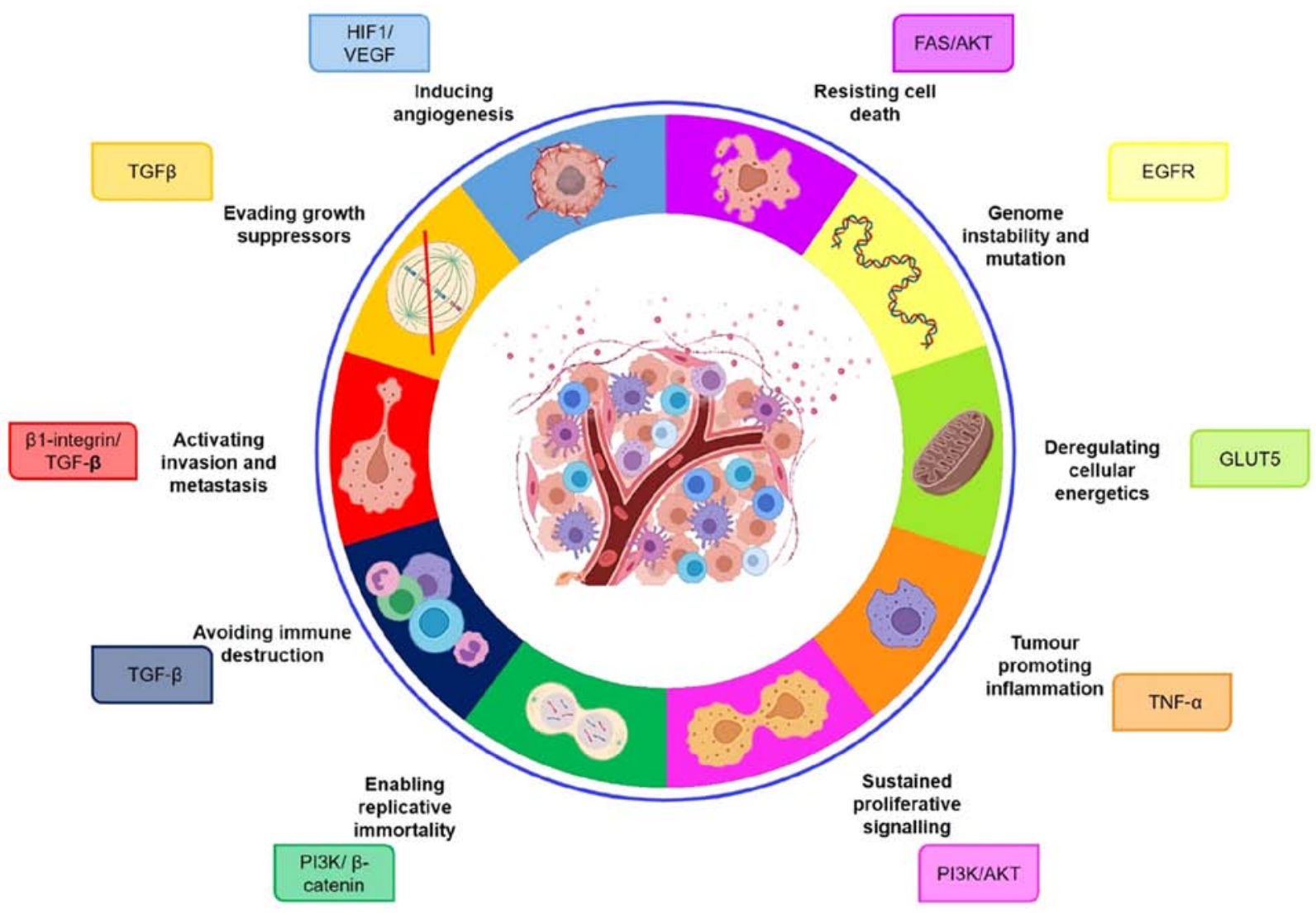

Figure 1. The role of ST6 $\beta$-galactoside $\alpha$-2,6-sialyltransferase 1 in the hallmarks of cancer. Image created using BioRender.

confer tumour resistance to anti-VEGF treatment. Levels of ST6GAL1 were elevated in tumours sensitive to anti-VEGF treatment, and ST6GAL1 knockdown protected tumours from anti-VEGF treatment $(22,67)$. In line with this, knockdown of ST6GAL1 in an osteosarcoma cell line also reduced levels of VEGF (22), suggesting a major role for ST6GAL1 in cancer associated angiogenesis.

Tumour metabolism and hypoxia play a key part in promoting the formation of new blood vessels through the activation of several pro-angiogenic factors $(62,69)$. The major determinant of hypoxia mediated angiogenesis is HIF1, a protein capable of upregulating VEGF and PI3K signalling in the absence of oxygen to promote the growth of new vessels $(69,70)$. Hypoxia experiments carried out in ovarian and pancreatic cancer cell lines indicate increased ST6GAL1 expression can lead to an accumulation of HIF1 $\alpha$ under hypoxic conditions, as well as increases in HIF1 $\alpha$ transcriptional targets (20). These increases suggest upregulated ST6GAL1 confers pro-survival characteristics under hypoxic conditions. Taken alongside evidence of ST6GAL1 as a major regulator of VEGF signalling, this suggests ST6GAL1 is an important sialyltransferase critical for angiogenesis.

Resisting cell death. It is well established that for a cancer to develop it must evade and overcome cellular apoptosis (71-73). Apoptosis is the programmed death of a cell, central for ensuring the correct cell turnover and development, so much so that aberrant apoptosis has been implicated in several human diseases, including cancer (74). For this reason, research into the mechanisms which underpin cell death has exploded over the past two decades, and we now have a fair understanding of the prominent molecular processes which regulate apoptosis (75). Glycan changes have been linked to apoptosis since the late 1990s (76-80), and sialylation (including ST6GAL1 mediated sialylation) has been functionally associated with the programmed cell death of several different cell types $(21,81-83)$. The TNF family of death receptors regulate programmed cell death, and include proteins such as DR4, DR5 and FAS. In a colon cancer model, ST6GAL1 upregulation can decrease levels of FAS mediated cell death (independent of both DR4 and DR5) through direct sialylation of the FAS protein (84). As mentioned earlier, elevated levels of ST6GAL1 drive hyper-activated AKT signalling in several cancer models, a key pathway which can be upregulated to enable tumour cells to evade apoptosis $(85,86)$. Due to the large number of downstream targets of PI3K signalling, the effect of ST6GAL sialylation on this pathway may result in changes in both cell survival and cellular proliferation. This, taken with evidence that a key TNF death receptor is a direct target of ST6GAL1, indicates that ST6GAL1 upregulation can confer anti-apoptotic characteristics.

Evading growth suppressors. Tumour suppressor genes negatively regulate cell proliferation and tumour growth and are vital 'gate-keepers' of the genome (87). A key feature of cancer cells is their ability to inactivate or avoid these growth suppressing signals to continue hyper-proliferation $(4,5)$. Several known tumour suppressor genes have been identified as targets of abnormal glycosylation, thereby promoting tumourigenesis $(2,88)$. Although in all other cancers sialylation 
Table I. Studies on ST6GAL1 in cancer.

\begin{tabular}{|c|c|c|c|c|}
\hline Author, year & Cancer & Role of ST6GAL1 & Characteristics & (Refs.) \\
\hline Antony et al, 2014 & Bladder & Downregulated & Invasive, high grade tumours with metastasis & $(31)$ \\
\hline Lu et al, 2014 & Breast & Upregulated & Metastatic disease & $(17)$ \\
\hline Wang et al, 2003 & Cervical & Upregulated & Stromal invasion with malignant disease & $(43)$ \\
\hline $\begin{array}{l}\text { Swindall et al, 2011; } \\
\text { Chiricolo et al, 2006; } \\
\text { Schultz et al, } 2016\end{array}$ & Colon & Upregulated & $\begin{array}{l}\text { Invasive, aggressive disease with } \\
\text { chemoresistance }\end{array}$ & $(84,107,108)$ \\
\hline Gretschel et al, 2003 & Gastric & Upregulated & Metastatic disease & $(109)$ \\
\hline Yamamoto et al, 2001 & Glioma & Upregulated & $\begin{array}{l}\text { More advanced invasive disease linked } \\
\text { to metastasis }\end{array}$ & $(23)$ \\
\hline Ma et al, 2015 & Leukemia & Upregulated & Increased chemoresistance & $(110)$ \\
\hline $\begin{array}{l}\text { Zhao et al, 2014; } \\
\text { Pousset et al, } 1997\end{array}$ & Liver & Upregulated & $\begin{array}{l}\text { More aggressive, invasive disease with } \\
\text { chemoresistance }\end{array}$ & $(42,111)$ \\
\hline Agrawal et al, 2017 & Melanoma & Upregulated & Metastatic disease & $(29)$ \\
\hline $\begin{array}{l}\text { Wang et al, 2005; } \\
\text { Wichert et al, } 2018\end{array}$ & Ovarian & Upregulated & Advanced invasive & $(7,18)$ \\
\hline Hsieh et al, 2017 & $\begin{array}{l}\text { Pancreatic disease with } \\
\text { distant metastasis }\end{array}$ & Upregulated & Advanced metastatic disease & $(15)$ \\
\hline $\begin{array}{l}\text { Wei et al, 2016; } \\
\text { Munkley et al, } 2016\end{array}$ & Prostate & Upregulated & Poor patient prognosis and metastatic disease & $(16,26)$ \\
\hline
\end{tabular}

ST6GAL1, ST6 $\beta$-galactoside $\alpha$-2,6-sialyltransferase 1 .

by ST6GAL1 appears to be a pro-oncogenic event, upregulation of the sialyltransferase in bladder cancer appears to have a tumour suppressive role, with low ST6GAL1 expression being a feature of more advanced invasive disease, and upregulation of ST6GAL1 a hallmark of non-invasive disease (31). This obvious contradiction with evidence from other cancer types highlights the heterogeneous role of ST6GAL1 activity in cancer. It is useful to note the functional association between ST6GAL1 directed sialylation and TGF $\beta$ signalling, as TGF $\beta$ has been identified as both a tumour suppressor gene and a cytokine capable of promoting oncogenic events (89). The complex nature of cancer disease biology and of sialylation may mean that ST6GAL1 has dual roles in both promoting and inhibiting cancer progression.

The enabling characteristics and emerging hallmarks of cancer. In 2011, Hanahan and Weinberg revisited their original hallmarks of cancer and proposed two emerging hallmarks, 'deregulating cellular energetics' and 'avoiding immune destruction'. They also identified two enabling characteristics, 'promoting inflammation' and 'genome instability and mutation' as crucial in the acquisition of the cancer hallmarks (5). Consistent with the previous hallmarks of cancer, ST6GAL1 appears to have important interactions with pathways important in the 'next generation' hallmarks of cancer. An anomaly of cancer cell biology is that even in the presence of oxygen, cancer cells will fuel themselves using aerobic glycolysis-a phenomenon now termed the 'Warburg effect' (90). This metabolic reprograming allows cancer cells to thrive and meet the energetic demands of their proliferative capacity, and has been shown to be associated with changes in glycosylation $(91,92)$. This need to proliferative often leaves cells in a glucose deficit, at which point other sugar substrates are utilised to sustain tumour growth (93). High dietary intake of fructose has been linked to increased risk of pancreatic cancer, and also linked to metastatic pancreatic cancer (15). In the same study, ST6GAL1 was found to be increased in metastatic disease, in a fructose dependant manner and through regulation by the GLUT5 fructose receptor. This link with GLUT5 suggests a possible link to sialylation by ST6GAL1 and metabolic reprogramming of cancer cells.

The ability of cancer cells to avoid immune destruction, through activation of immune suppressors allows for uninterrupted tumour growth and progression (94). As mentioned earlier, there is a mechanistic link between TGF- $\beta$ signalling and ST6GAL1 directed sialylation. TGF- $\beta$ is a known immunosuppresor gene, important in the regulation of helper T-cells and regulatory $\mathrm{T}$-cells, inhibiting cytokine production and suppressing macrophages, dendritic cells and natural killer cells $(95,96)$. Although the association between TGF- $\beta$ and ST6GAL1 is better understood in the context of EMT, there may be a role for sialylation in allowing cancer cells to evade immune destruction through this TGF- $\beta$ interaction. At odds with the idea that immune cells seek to destroy cancer cells, the evidence now suggests that some infiltrating immune cells promote tumourigenesis, contributing growth factors, survival factors and pro-angiogenic factors which all help to sustain the tumour microenvironment (97-99). Glycosylation, and in 
particular sialylation is known to play an important role in regulation of the immune response $(100,101)$. ST6GAL1-null mice exhibit a widespread immunodeficient phenotype, indicating that ST6GAL1 sialylation is integral to regulation of the immune system (102). ST6GAL1 has been shown to promote $B$ cell activation. IgG has also been shown to be a direct target for ST6GAL1 sialylation in an estrogen dependant manner in rheumatoid arthritis (103). It is evident that immune signalling is a substrate for regulation by sialylation, however much more needs to be done to characterise the effect of ST6GAL1 on the immune system (104). Regulation of the immune response through aberrant sialylation could result in tumour promoting inflammation.

Genomic instability and an accumulation of genomic mutations underpin carcinogenesis in all cancer subsets. In an attempt to avoid instability, DNA damage sensors actively survey the genome for DNA damage, and upon recognition of mutations activate DNA repair pathways. Mutation or inactivation of these repair pathways, such as the p53 signalling pathway, will inevitably result in mutational accumulation. An upstream regulator of DNA repair pathways is EGFR, known to regulate DNA repair, DNA replication and maintenance of genome stability when found in the nucleus (105). A study of ST6GAL1 sialylation in ovarian cancer, suggested that increased ST6GAL1 sialylation confers resistance to chemotherapeutic intervention (106). Of interest, they postulated that this chemoresistance was through direct sialylation of EGFR by ST6GAL1, resulting in heightened activation of EGFR. This suggests a direct mechanistic link between ST6GAL1-sialylation and DNA damage repair and implicates ST6GAL1 in the maintenance of genome stability.

\section{Conclusions and future perspectives}

The hallmarks of cancer are crucial to our understanding of cancer cell biology, and in guiding our efforts to identify novel biomarkers and develop new therapeutic strategies. Aberrant glycosylation is a universal feature of cancer cells, and glycans can modulate several of the pathways intrinsic to tumour cell biology. Here, we suggest that the sialyltransferase enzyme ST6GAL1 has widespread applications in the study of cancer, and importantly is implicated in all of the recognised cancer hallmarks (Fig. 1). Given the widespread impact of sialylation in cancer, and the evident prognostic value of ST6GAL1 levels, an improved understanding of how ST6GAL1 mediated sialylation sustains cancer cell biology may open the door to a new range of cancer therapeutics.

\section{Acknowledgements}

Not applicable.

\section{Funding}

The present study was supported by Prostate Cancer UK through a Research Innovation Award (grant no. RIA16-ST2-011).

\section{Availability of data and materials}

Not applicable.

\section{Authors' contributions}

RG, ES, KEL and JM jointly conceived and designed the review, researched the literature and wrote the manuscript.

\section{Ethics approval and consent to participate}

Not applicable.

\section{Patient consent for publication}

Not applicable.

\section{Competing interests}

The authors declare that they have no competing interest.

\section{References}

1. Varki A: Biological roles of glycans. Glycobiology 27: 3-49, 2017

2. Pinho SS and Reis CA: Glycosylation in cancer: Mechanisms and clinical implications. Nat Rev Cancer 15: 540-555, 2015.

3. Munkley J and Elliott DJ: Hallmarks of glycosylation in cancer. Oncotarget 7: 35478-35489, 2016.

4. Hanahan D and Weinberg RA: The hallmarks of cancer. Cell 100: 57-70, 2000.

5. Hanahan D and Weinberg RA: Hallmarks of cancer: The next generation. Cell 144: 646-674, 2011.

6. Vajaria BN and Patel PS: Glycosylation: A hallmark of cancer? Glycoconj J 34: 147-156, 2017.

7. Wang PH, Lee WL, Juang CM, Yang YH, Lo WH, Lai CR, Hsieh SL and Yuan CC: Altered mRNA expressions of sialyltransferases in ovarian cancers. Gynecol Oncol 99: 631-639, 2005.

8. Bhide GP and Colley KJ: Sialylation of N-glycans: Mechanism, cellular compartmentalization and function. Histochem Cell Biol 147: 149-174, 2017.

9. Munkley J, Oltean S, Vodak D, Wilson BT, Livermore KE, Zhou Y, Star E, Floros VI, Johannessen B, Knight B, et al: The androgen receptor controls expression of the cancer-associated sTn antigen and cell adhesion through induction of ST6GalNAc1 in prostate cancer. Oncotarget 6: 34358-34374, 2015.

10. Vajaria BN, Patel KR, Begum R and Patel PS: Sialylation: An Avenue to Target Cancer Cells. Pathol Oncol Res 22: 443-447, 2016.

11. Munkley J: The role of Sialyl-Tn in cancer. Int J Mol Sci 17: 275, 2016.

12. Scott E and Munkley J: Glycans as biomarkers in prostate cancer. Int J Mol Sci 20: E1389, 2019.

13. Zhang Z, Wuhrer M and Holst S: Serum sialylation changes in cancer. Glycoconj J 35: 139-160, 2018.

14. Dall'Olio F: The sialyl-alpha2,6-lactosaminyl-structure: Biosynthesis and functional role. Glycoconj J 17: 669-676, 2000.

15. Hsieh CC, Shyr YM, Liao WY, Chen TH, Wang SE, Lu PC, Lin PY, Chen YB, Mao WY, Han HY, et al: Elevation of $\beta$-galactoside $\alpha 2,6$-sialyltransferase 1 in a fructoseresponsive manner promotes pancreatic cancer metastasis. Oncotarget 8: 7691-7709, 2017.

16. Wei A, Fan B, Zhao Y, Zhang H, Wang L, Yu X, Yuan Q, Yang D and Wang S: ST6Gal-I overexpression facilitates prostate cancer progression via the PI3K/Akt/GSK-3 $\beta / \beta$-catenin signaling pathway. Oncotarget 7: 65374-65388, 2016.

17. Lu J, Isaji T, Im S, Fukuda T, Hashii N, Takakura D, Kawasaki N and $\mathrm{Gu} \mathrm{J}$ : $\beta$-Galactoside $\alpha 2,6$-sialyltranferase 1 promotes transforming growth factor- $\beta$-mediated epithelial-mesenchymal transition. J Biol Chem 289: 34627-34641, 2014.

18. Wichert B, Milde-Langosch K, Galatenko V, Schmalfeldt B and Oliveira-Ferrer L: Prognostic role of the sialyltransferase ST6GAL1 in ovarian cancer. Glycobiology 28: 898-903, 2018.

19. Hebbar M, Krzewinski-Recchi MA, Hornez L, Verdière A, Harduin-Lepers A, Bonneterre J, Delannoy P and Peyrat JP: Prognostic value of tumoral sialyltransferase expression and circulating E-selectin concentrations in node-negative breast cancer patients. Int J Biol Markers 18: 116-122, 2003. 
20. Jones RB, Dorsett KA, Hjelmeland AB and Bellis SL: The ST6Gal-I sialyltransferase protects tumor cells against hypoxia by enhancing HIF-1 $\alpha$ signaling. J Biol Chem 293: 5659-5667, 2018.

21. Liu Z, Swindall AF, Kesterson RA, Schoeb TR, Bullard DC and Bellis SL: ST6Gal-I regulates macrophage apoptosis via a2-6 sialylation of the TNFR1 death receptor. J Biol Chem 286: 39654-39662, 2011.

22. Meng Q, Ren C, Wang L, Zhao Y and Wang S: Knockdown of ST6Gal-I inhibits the growth and invasion of osteosarcoma MG-63 cells. Biomed Pharmacother 72: 172-178, 2015.

23. Yamamoto H, Oviedo A, Sweeley C, Saito T and Moskal JR: Alpha2,6-sialylation of cell-surface N-glycans inhibits glioma formation in vivo. Cancer Res 61: 6822-6829, 2001.

24. Zhao Y, Wei A, Zhang H, Chen X, Wang L, Zhang H, Yu X, Yuan Q, Zhang J and Wang S: $\alpha 2,6-$ Sialylation mediates hepatocellular carcinoma growth in vitro and in vivo by targeting the Wnt//-catenin pathway. Oncogenesis 6: e343, 2017.

25. Munkley J: Glycosylation is a global target for androgen control in prostate cancer cells. Endocr Relat Cancer 24: R49-R64, 2017.

26. Munkley J, Vodak D, Livermore KE, James K, Wilson BT, Knight B, Mccullagh P, Mcgrath J, Crundwell M,Harries LW, et al: Glycosylation is an androgen-regulated process essential for prostate cancer cell viability. EBioMedicine 8: 103-116, 2016.

27. Recchi MA, Hebbar M, Hornez L, Harduin-Lepers A, Peyrat JP and Delannoy P: Multiplex reverse transcription polymerase chain reaction assessment of sialyltransferase expression in human breast cancer. Cancer Res 58: 4066-4070, 1998.

28. Bassaganas S, Allende H, Cobler L, Ortiz MR, Llop E, de Bolós C and Peracaula R: Inflammatory cytokines regulate the expression of glycosyltransferases involved in the biosynthesis of tumor-associated sialylated glycans in pancreatic cancer cell lines. Cytokine 75: 197-206, 2015.

29. Agrawal P, Fontanals-Cirera B, Sokolova E, Jacob S, Vaiana CA, Argibay D, Davalos V, McDermott M, Nayak S, Darvishian F, et al: A Systems biology approach identifies FUT8 as a driver of melanoma metastasis. Cancer Cell 31: 804-819.e7, 2017.

30. Munkley J: The glycosylation landscape of pancreatic cancer. Oncol Lett 17: 2569-2575, 2019.

31. Antony P, Rose M, Heidenreich A, Knuchel R, Gaisa NT and Dahl E: Epigenetic inactivation of ST6GAL1 in human bladder cancer. BMC Cancer 14: 901, 2014.

32. Jin K, Li T, van Dam H, Zhou F and Zhang L: Molecular insights into tumour metastasis: Tracing the dominant events. J Pathol 241: 567-577, 2017.

33. Montanari M, Rossetti S, Cavaliere C, D'Aniello C, Malzone MG, Vanacore D, Di Franco R, La Mantia E, Iovane G, Piscitelli R, et al: Epithelial-mesenchymal transition in prostate cancer: An overview. Oncotarget 8: 35376-35389, 2017.

34. Goossens S, Vandamme N, Van Vlierberghe P and Berx G: EMT transcription factors in cancer development re-evaluated Beyond EMT and MET. Biochim Biophys Acta Rev Cancer 1868 584-591, 2017.

35. Park JJ and Lee M: Increasing the $\alpha 2,6$ sialylation of glycoproteins may contribute to metastatic spread and therapeutic resistance in colorectal cancer. Gut Liver 7: 629-641, 2013.

36. Ju T, Wang Y, Aryal RP, Lehoux SD, Ding X, Kudelka MR, Cutler C, Zeng J, Wang J, Sun X, et al: Tn and sialyl-Tn antigens, aberrant $\mathrm{O}$-glycomics as human disease markers. Proteomics. Proteomics Clin Appl 7: 618-631, 2013.

37. Schultz MJ, Swindall AF and Bellis SL: Regulation of the metastatic cell phenotype by sialylated glycans. Cancer Metastasis Rev 31: 501-518, 2012

38. Kannagi R, Izawa M, Koike T, Miyazaki K and Kimura N: Carbohydrate-mediated cell adhesion in cancer metastasis and angiogenesis. Cancer Sci 95: 377-384, 2004.

39. Irimura $\mathrm{T}$, Nakamori $\mathrm{S}$, Matsushita $\mathrm{Y}$, Taniuchi $\mathrm{Y}$, Todoroki $\mathrm{N}$, Tsuji T, Izumi Y, Kawamura Y, Hoff SD, Cleary KR, et al: Colorectal cancer metastasis determined by carbohydrate-mediated cell adhesion: Role of sialyl-LeX antigens. Semin Cancer Biol 4: 319-324, 1993.

40. Ugorski M and Laskowska A: Sialyl Lewis(a): A tumor-associated carbohydrate antigen involved in adhesion and metastatic potential of cancer cells. Acta Biochim Pol 49: 303-311, 2002.

41. Murugaesu N, Iravani M, van Weverwijk A, Ivetic A, Johnson DA, Antonopoulos A, Fearns A, Jamal-Hanjani M, Sims D, Fenwick K, et al: An in vivo functional screen identifies ST6GalNAc2 sialyltransferase as a breast cancer metastasis suppressor. Cancer Discov 4: 304-317, 2014.
42. Zhao Y, Li Y, Ma H, Dong W, Zhou H, Song X, Zhang J and Jia L: Modification of sialylation mediates the invasive properties and chemosensitivity of human hepatocellular carcinoma. Mol Cell Proteomics 13: 520-536, 2014.

43. Wang PH, Lee WL, Lee YR, Juang CM, Chen YJ, Chao HT, Tsai YC and Yuan CC: Enhanced expression of alpha 2,6-sialyltransferase ST6Gal I in cervical squamous cell carcinoma. Gynecol Oncol 89: 395-401, 2003.

44. Lin S, Kemmner W, Grigull S and Schlag PM: Cell surface alpha 2,6 sialylation affects adhesion of breast carcinoma cells. Exp Cell Res 276: 101-110, 2002.

45. Feitelson MA, Arzumanyan A, Kulathinal RJ, Blain SW, Holcombe RF, Mahajna J, Marino M, Martinez-Chantar ML, Nawroth R, Sanchez-Garcia I, et al: Sustained proliferation in cancer: Mechanisms and novel therapeutic targets. Semin Cancer Biol 35 (Suppl): S25-S54, 2015.

46. Ma X, Dong W, Su Z, Zhao L, Miao Y, Li N, Zhou H and Jia L: Functional roles of sialylation in breast cancer progression through miR-26a/26b targeting ST8SIA4. Cell Death Dis 7: e2561, 2016.

47. Luo J, Manning BD and Cantley LC: Targeting the PI3K-Akt pathway in human cancer: Rationale and promise. Cancer Cell 4: 257-262, 2003

48. Tokunaga E, Kimura Y, Mashino K, Oki E, Kataoka A, Ohno S, Morita M, Kakeji Y, Baba H and Maehara Y: Activation of PI3K/Akt signaling and hormone resistance in breast cancer. Breast Cancer 13: 137-144, 2006.

49. Deying W, Feng G, Shumei L, Hui Z, Ming L and Hongqing W: CAF-derived HGF promotes cell proliferation and drug resistance by up-regulating the c-Met/PI3K/Akt and GRP78 signalling in ovarian cancer cells. Biosci Rep 37: BSR20160470, 2017.

50. De Marco C, Laudanna C, Rinaldo N, Oliveira DM, Ravo M, Weisz A, Ceccarelli M, Caira E, Rizzuto A, Zoppoli P, et al: Specific gene expression signatures induced by the multiple oncogenic alterations that occur within the PTEN/PI3K/AKT pathway in lung cancer. PLoS One 12: e0178865, 2017.

51. Yaswen P, MacKenzie KL, Keith WN, Hentosh P, Rodier F, Zhu J, Firestone GL, Matheu A, Carnero A, Bilsland A, et al: Therapeutic targeting of replicative immortality. Semin Cancer Biol 35 (Suppl): S104-S128, 2015.

52. Roninson IB: Tumor cell senescence in cancer treatment. Cancer Res 63: 2705-2715, 2003.

53. Braig M and Schmitt CA: Oncogene-induced senescence: Putting the brakes on tumor development. Cancer Res 66: 2881-2884, 2006.

54. Lin AW and Lowe SW: Oncogenic ras activates the ARF-p53 pathway to suppress epithelial cell transformation. Proc Natl Acad Sci USA 98: 5025-5030, 2001.

55. Courtois-Cox S, Jones SL and Cichowski K: Many roads lead to oncogene-induced senescence. Oncogene 27: 2801-2809, 2008.

56. Chou TY, Hart GW and Dang CV: c-Myc is glycosylated at threonine 58, a known phosphorylation site and a mutational hot spot in lymphomas. J Biol Chem 270: 18961-18965, 1995.

57. Castellano E and Downward J: RAS interaction with PI3K: More than just another effector pathway. Genes Cancer 2: 261-274, 2011.

58. Delmas V, Beermann F, Martinozzi S, Carreira S, Ackermann J, Kumasaka M, Denat L, Goodall J, Luciani F, Viros A, et al: Beta-catenin induces immortalization of melanocytes by suppressing p16INK4a expression and cooperates with N-Ras in melanoma development. Genes Dev 21: 2923-2935, 2007.

59. Zhang Y, Toh L, Lau P and Wang X: Human telomerase reverse transcriptase (hTERT) is a novel target of the Wnt/ $\beta$-catenin pathway in human cancer. J Biol Chem 287: 32494-32511, 2012.

60. Eelen G, Dubois C, Cantelmo AR, Goveia J, Brüning U, DeRan M, Jarugumilli G, van Rijssel J, Saladino G, Comitani F, et al: Role of glutamine synthetase in angiogenesis beyond glutamine synthesis. Nature 561: 63-69, 2018.

61. Hanahan D and Folkman J: Patterns and emerging mechanisms of the angiogenic switch during tumorigenesis. Cell 86: 353-364, 1996.

62. De Palma M, Biziato D and Petrova TV: Microenvironmental regulation of tumour angiogenesis. Nat Rev Cancer 17: 457-474, 2017.

63. Chiodelli P, Rezzola S, Urbinati C, Federici Signori F, Monti E, Ronca R, Presta M and Rusnati M: Contribution of vascular endothelial growth factor receptor-2 sialylation to the process of angiogenesis. Oncogene 36: 6531-6541, 2017.

64. Cheng WK and Oon CE: How glycosylation aids tumor angiogenesis: An updated review. Biomed Pharmacother 103: 1246-1252, 2018. 
65. Croci DO, Cerliani JP, Pinto NA, Morosi LG and Rabinovich GA Regulatory role of glycans in the control of hypoxia-driven angiogenesis and sensitivity to anti-angiogenic treatment. Glycobiology 24: 1283-1290, 2014.

66. Lynch TP, Ferrer CM, Jackson SR, Shahriari KS, Vosseller K and Reginato MJ: Critical role of O-Linked beta-N-acetylglucosamine transferase in prostate cancer invasion, angiogenesis, and metastasis. J Biol Chem 287: 11070-11081, 2012.

67. Croci DO, Cerliani JP, Dalotto-Moreno T, Méndez-Huergo SP, Mascanfroni ID, Dergan-Dylon S, Toscano MA, Caramelo JJ, García-Vallejo JJ, Ouyang J, et al: Glycosylation-dependent lectin-receptor interactions preserve angiogenesis in anti-VEGF refractory tumors. Cell 156: 744-758, 2014

68. Croci DO and Rabinovich GA: Linking tumor hypoxia with VEGFR2 signaling and compensatory angiogenesis: Glycans make the difference. Oncoimmunology 3: e29380, 2014.

69. LaGory EL and Giaccia AJ: The ever-expanding role of HIF in tumour and stromal biology. Nat Cell Biol 18: 356-365, 2016.

70. Zhang W, Xiong Z, Wei T, Li Q, Tan Y,Ling L and Feng X: Nuclear factor 90 promotes angiogenesis by regulating HIF-1 $\alpha / \mathrm{VEGF}-\mathrm{A}$ expression through the PI3K/Akt signaling pathway in human cervical cancer. Cell Death Dis 9: 276, 2018.

71. Evans EK and Kornbluth S: Regulation of apoptosis in Xenopus egg extracts. Adv Enzyme Regul 38: 265-280, 1998.

72. Lowe M, Lane JD, Woodman PG and Allan VJ: Caspase-mediated cleavage of syntaxin 5 and giantin accompanies inhibition of secretory traffic during apoptosis. J Cell Sci 117: 1139-1150, 2004

73. Kerr JF: History of the events leading to the formulation of the apoptosis concept. Toxicology 181-182: 471-474, 2002.

74. Fernald $\mathrm{K}$ and Kurokawa M: Evading apoptosis in cancer. Trends Cell Biol 23: 620-633, 2013.

75. Adams JM and Cory S: Bcl-2-regulated apoptosis: Mechanism and therapeutic potential. Curr Opin Immunol 19: 488-496, 2007.

76. Walker BK, Lei H and Krag SS: A functional link between $\mathrm{N}$-linked glycosylation and apoptosis in Chinese hamster ovary cells. Biochem Biophys Res Commun 250: 264-270, 1998.

77. Zhang D, Liu X, Gao J, Sun Y, Liu T, Yan Q and Yang X: The role of epithelial cell adhesion molecule $\mathrm{N}$-glycosylation on apoptosis in breast cancer cells. Tumour Biol 39: 1010428317695973, 2017.

78. Rapoport E and Pendu JL: Glycosylation alterations of cells in late phase apoptosis from colon carcinomas. Glycobiology 9: $1337-1345,1999$

79. Gwak H, Kim S, Dhanasekaran DN and Song YS: Resveratrol triggers ER stress-mediated apoptosis by disrupting N-linked glycosylation of proteins in ovarian cancer cells. Cancer Lett 371: 347-353, 2016

80. Seyrek K, Richter M and Lavrik IN: Decoding the sweet regulation of apoptosis: The role of glycosylation and galectins in apoptotic signaling pathways. Cell Death Differ 26: 981-993, 2019.

81. Suzuki O, Abe M and Hashimoto Y: Caspase-dependent drug-induced apoptosis is regulated by cell surface sialylation in human B-cell lymphoma. Oncol Lett 10: 687-690, 2015.

82. Meesmann HM, Fehr EM, Kierschke S, Herrmann M, Bilyy R, Heyder P, Blank N, Krienke S, Lorenz HM and Schiller M: Decrease of sialic acid residues as an eat-me signal on the surface of apoptotic lymphocytes. J Cell Sci 123: 3347-3356, 2010.

83. Peter ME, Hellbardt S, Schwartz-Albiez R, Westendorp MO Walczak H, Moldenhauer G, Grell M and Krammer PH: Cel surface sialylation plays a role in modulating sensitivity towards APO-1-mediated apoptotic cell death. Cell Death Differ 2: $163-171,1995$.

84. Swindall AF and Bellis SL: Sialylation of the Fas death receptor by ST6Gal-I provides protection against Fas-mediated apoptosi in colon carcinoma cells. J Biol Chem 286: 22982-22990, 2011.

85. Yao R and Cooper GM: Requirement for phosphatidylinositol-3 kinase in the prevention of apoptosis by nerve growth factor. Science 267: 2003-2006, 1995.

86. Franke TF, Kaplan DR and Cantley LC: PI3K: Downstream AKTion blocks apoptosis. Cell 88: 435-437, 1997.

87. Burkhart DL and Sage J: Cellular mechanisms of tumour suppression by the retinoblastoma gene. Nat Rev Cancer 8: 671-682, 2008.

88. Masuda M, Yageta M, Fukuhara H, Kuramochi M, Maruyama T, Nomoto A and Murakami Y: The tumor suppressor protein TSLC1 is involved in cell-cell adhesion. J Biol Chem 277: 31014-31019, 2002.

89. Bierie B and Moses HL: TGF-beta and cancer. Cytokine Growth Factor Rev 17: 29-40, 2006.
90. Warburg O, Wind F and Negelein E: The metabolism of tumors in the body. J Gen Physiol 8: 519-530, 1927.

91. Ferrer CM,Lynch TP, Sodi VL, Falcone JN, SchwabLP,Peacock DL, Vocadlo DJ, Seagroves TN and Reginato MJ: O-GlcNAcylation regulates cancer metabolism and survival stress signaling via regulation of the HIF-1 pathway. Mol Cell 54: 820-831, 2014.

92. Ferrer CM and Reginato MJ: Sweet connections: O-GlcNAcylation links cancer cell metabolism and survival. Mol Cell Oncol 2: e961809, 2014.

93. Chen WL, Wang YY, Zhao A, Xia L, Xie G, Su M, Zhao L, Liu J, Qu C, Wei R, et al: Enhanced fructose utilization mediated by SLC2A5 is a unique metabolic feature of acute myeloid leukemia with therapeutic potential. Cancer Cell 30: 779-791, 2016.

94. Vinay DS, Ryan EP, Pawelec G, Talib WH, Stagg J, Elkord E, Lichtor T, Decker WK, Whelan RL, Kumara HMCS, et al: Immune evasion in cancer: Mechanistic basis and therapeutic strategies. Semin Cancer Biol 35 (Suppl): S185-S198, 2015.

95. Wrzesinski SH, Wan YY and Flavell RA: Transforming growth factor-beta and the immune response: Implications for anticancer therapy. Clin Cancer Res 13: 5262-5270, 2007.

96. Yoshimura A and Muto G: TGF- $\beta$ function in immune suppression. Curr Top Microbiol Immunol 350: 127-147, 2011.

97. DeNardo DG, Andreu P and Coussens LM: Interactions between lymphocytes and myeloid cells regulate pro-versus anti-tumor immunity. Cancer Metastasis Rev 29: 309-316, 2010.

98. Qian BZ and Pollard JW: Macrophage diversity enhances tumor progression and metastasis. Cell 141: 39-51, 2010.

99. Colotta F, Allavena P, Sica A, Garlanda C and Mantovani A Cancer-related inflammation, the seventh hallmark of cancer: Links to genetic instability. Carcinogenesis 30: 1073-1081, 2009.

100. Dube DH and Bertozzi CR: Glycans in cancer and inflammation-potential for therapeutics and diagnostics. Nat Rev Drug Discov 4: 477-488, 2005

101. Marth JD and Grewal PK: Mammalian glycosylation in immunity. Nat Rev Immunol 8: 874-887, 2008.

102. Hennet T, Chui D, Paulson JC and Marth JD: Immune regulation by the ST6Gal sialyltransferase. Proc Natl Acad Sci USA 95 4504-4509, 1998.

103. Engdahl C, Bondt A, Harre U, Raufer J, Pfeifle R, Camponeschi A, Wuhrer M, Seeling M, Mårtensson IL, Nimmerjahn F, et al: Estrogen induces St6gall expression and increases IgG sialylation in mice and patients with rheumatoid arthritis: A potential explanation for the increased risk of rheumatoid arthritis in postmenopausal women. Arthritis Res Ther 20: 84, 2018

104. Perdicchio M, Ilarregui JM, Verstege MI, Cornelissen LA, Schetters ST, Engels S, Ambrosini M, Kalay H, Veninga H, den Haan JM, et al: Sialic acid-modified antigens impose tolerance via inhibition of T-cell proliferation and de novo induction of regulatory T cells. Proc Natl Acad Sci USA 113: 3329-3334, 2016

105. Chou RH, Wang YN, Hsieh YH, Li LY, Xia W, Chang WC, Chang LC, Cheng CC, Lai CC, Hsu JL, et al: EGFR modulates DNA synthesis and repair through Tyr phosphorylation of histone H4. Dev Cell 30: 224-237, 2014.

106. Britain CM, Holdbrooks AT, Anderson JC, Willey CD and Bellis SL: Sialylation of EGFR by the ST6Gal-I sialyltransferase promotes EGFR activation and resistance to gefitinib-mediated cell death. J Ovarian Res 11: 12, 2018.

107. Chiricolo M, Malagolini N, Bonfiglioli S and Dall'Olio F: Phenotypic changes induced by expression of beta-galactoside alpha2,6 sialyltransferase I in the human colon cancer cell line SW948. Glycobiology 16: 146-154, 2006.

108. Schultz MJ, Holdbrooks AT, Chakraborty A, Grizzle WE, Landen CN, Buchsbaum DJ, Conner MG, Arend RC, Yoon KJ, Klug CA, et al: The tumor-associated glycosyltransferase ST6Gal-I regulates stem cell transcription factors and confers a cancer stem cell phenotype. Cancer Res 76: 3978-3988, 2016.

109. Gretschel S, Haensch W, Schlag PM and Kemmner W: Clinical relevance of sialyltransferases ST6GAL-I and ST3GAL-III in gastric cancer. Oncology 65: 139-145, 2003.

110. Ma H, Zhou H, Song X, Shi S, Zhang J and Jia L: Modification of sialylation is associated with multidrug resistance in human acute myeloid leukemia. Oncogene 34: 726-740, 2015

111. Pousset D, Piller V, Bureaud N, Monsigny M and Piller F. Increased alpha2,6 sialylation of $\mathrm{N}$-glycans in a transgenic mouse model of hepatocellular carcinoma. Cancer Res 57: 4249-4256, 1997.

This work is licensed under a Creative Commons Attribution-NonCommercial-NoDerivatives 4.0 International (CC BY-NC-ND 4.0) License. 